\title{
Reactive Oxygen Species Production in the Early and Later Stage of Chronic Ventilatory Hypoxia
}

\author{
D. HODYC ${ }^{1}$, E. JOHNSON ${ }^{1}$, A. SKOUMALOVÁ ${ }^{2}$, J. TKACZYK ${ }^{3}$, H. MAXOVÁ ${ }^{3}$, \\ M. VÍZEK ${ }^{3}$, J. HERGET ${ }^{1}$
}

${ }^{1}$ Department of Physiology, Second Medical School, Charles University in Prague, Prague, Czech Republic, ${ }^{2}$ Department of Medical Chemistry and Biochemistry, Second Medical School, Charles University in Prague, Prague, Czech Republic, ${ }^{3}$ Department of Pathological Physiology, Second Medical School, Charles University in Prague, Prague, Czech Republic

Received April 6, 2011

Accepted January 5, 2012

On-line January 31, 2012

\section{Summary}

Pulmonary hypertension resulting from chronic hypoxia is at least partly caused by the increased production of reactive oxygen species (ROS). The goal of the presented study was to investigate the dynamics and the site of production of ROS during chronic hypoxia. In our study Wistar rats were kept for 1 , 4 and 21 days in an isobaric hypoxic chamber $\left(\mathrm{F}_{\mathrm{iO} 2}=0.1\right)$, while controls stayed in normoxia. We compared NO production in expired air, plasma and perfusate drained from isolated rat lungs and measured superoxide concentration in the perfusate. We also detected the presence of superoxide products (hydrogen peroxide and peroxynitrite) and the level of ROS-induced damage expressed as the concentration of lipid peroxydation end products. We found that the production and release of ROS and NO during early phase of chronic hypoxia has specific timing and differs in various compartments, suggesting the crucial role of ROS interaction for development of hypoxic pulmonary hypertension.

\section{Key words}

Free radicals $\bullet$ Nitric oxide $\bullet$ Chronic hypoxia $\bullet$ Oxidative stress $\bullet$ Pulmonary hypertension

\section{Corresponding author}

D. Hodyc, Department of Physiology, Second Medical School, Charles University in Prague, Plzeňská 221/130, 15000 Prague, Czech Republic. E-mail: daniel.hodyc@lfmotol.cuni.cz

\section{Introduction}

Exposure to chronic hypoxia causes hypoxic pulmonary hypertension (HPH), right ventricular hypertrophy and structural remodelling of prealveolar pulmonary arteries (Rabinovitch et al. 1979, Reid 1979). Pulmonary hypertension develops within the first 10 days of hypoxia and then does not progress any further (Herget and Palecek 1978).

It is accepted that chronic hypoxia in the early phases of exposure generates lung oxidant stress (Hoshikawa et al. 1995, Nakanishi et al. 1995). Oxidant stress of the walls of prealveolar pulmonary blood vessels is the important factor in the pathogenesis of pulmonary hypertension (Hampl and Herget 2000), since the inhibition of this free radical damage by antioxidants or by ROS scavengers prevented or attenuated the development of hypoxic pulmonary hypertension (Herget et al. 2000, Lachmanova et al. 2005). Recent studies indicated that pulmonary vascular-derived ROS originate predominantly from an enzymatic source (Jankov et al. 2008), including xanthine oxidase (Liu et al. 2006) and endothelial nitric oxide synthase (eNOS) converted to a superoxide-generating enzyme (eNOS uncoupling) (Cai and Harrison 2000, Chalupsky and Cai 2005). Both enzymes produce an increased amount of superoxide and its dismutation product, hydrogen peroxide. Hypoxia also increases the expression of inducible nitric oxide synthase (iNOS), accompanied by the increased production of nitric oxide in the pulmonary vessels (Hampl et al. 2006). 
In the presence of superoxide, nitric oxide readily creates peroxynitrite (Beckman and Koppenol 1996), another free radical important for hypoxic vascular damage (Belik et al. 2004). Therefore, the time dynamics and sequence of NO and ROS production in the first days of hypoxia seem to be influenced by many factors. There are, however, several uncertainties concerning the source, nature and pathogenic role of the hypoxia-induced release of reactive oxygen species. Thus, the goal of the presented study was to investigate the dynamics and the site of production of superoxide (and its dismutation product hydrogen peroxide), the dynamics of nitric oxide, its product peroxynitrite and the level of ROS-induced damage (expressed as the concentration of lipid peroxidation end products, LFP) in different stages of sub-acute and chronic hypoxia.

\section{Methods}

Experiments were performed on adult male rats in accordance with the Guide for the Care and Use of Laboratory Animals (1985), NIH, Bethesda, and European Guidelines on Laboratory Animal Care. All procedures were approved by the Animal Studies Committee in the authors' institution.

\section{Measurement of nitric oxide in expired air}

Wistar male rats were divided into 4 groups. Three of them, experimental groups, were exposed to hypoxia in an isobaric hypoxic chamber (Hampl and Herget 1990) $\left(\mathrm{F}_{\mathrm{iO} 2}=0.1\right)$ for 1 day $(\mathrm{H} 1, \mathrm{n}=8), 4$ days $(\mathrm{H} 4$, $\mathrm{n}=8)$ and 21 days $(\mathrm{H} 21, \mathrm{n}=8)$. The control group of animals was kept in atmospheric air (normoxic group, $\mathrm{N}$, $\mathrm{n}=8$ ). All the measurements reported below were taken consecutively on the same animals; a separate experiment was set only for hydrogen peroxide detection.

Immediately after the removal of the rats from the hypoxic chamber, the NO in expired air was measured. The rats were kept individually in glass jars (2 1) flushed with air without NO. The nitric oxide accumulated in the jar after 15 minutes was measured using a chemiluminescence NO analyzer as described previously (Hampl et al. 2006).

Blood sampling, measurement of NOx in plasma, nitrotyrosine and LFP

After completing the measurement of $\mathrm{NO}$ in expired air, the rats were anesthetised with thiopental (30 mg/kg b.w. administered i.p.) and ventilated with air through tracheal cannula $(50$ breaths/min; peak inspiratory pressure of $10 \mathrm{~cm} \mathrm{H}_{2} \mathrm{O}$, positive end expiratory pressure $2 \mathrm{~cm} \mathrm{H}_{2} \mathrm{O}$ ). The chest was opened and blood samples were collected from the left heart ventricle for the measurement of plasma nitrotyrosine concentration, plasma concentration of $\mathrm{NO}$ and its oxidation products (NOx) and lipufuscin-like pigments (lipid peroxidation end products) in erythrocyte membranes.

The plasma concentration of $\mathrm{NO}$ and its oxidation products (nitrites and nitrates, NOx) were measured with a chemiluminescence NO analyzer using the methods described earlier (Hampl et al. 2006, Sun et al. 2010).

Because the nitration of tyrosine in proteins in plasma produces nitrotyrosine, we used the plasma nitrotyrosine concentrations as a marker of peroxynitrite production (Beckman 1996). Nitrotyrosine was measured by inhibition ELISA as already described (Herget et al. 2000). Polystyrene plates were briefly coated with nitrated serum albumin and incubated with monoclonal antibody (NO-60-E3, prepared in our laboratory) and diluted serum samples. After washing, the plates were then incubated with anti-mouse IgG conjugated with peroxidise (A-8924, Sigma) and developed with o-phenylenediamine.

It has been reported many times that the exposure of different cell membranes to free radical injury leads to the production of lipid peroxidation end products (LFP). Thus we used the measurement of LFP production in erythrocytes (Goldstein and McDonagh 1976, Wilhelm and Herget 1999b) as a marker of oxidative injury.

Isolated perfused rat lungs, measurement of NOx and superoxide production

After taking the blood samples, the preparation of isolated, salt-solution-perfused lungs was completed as previously described (Herget et al. 1987, Hampl and Herget 1990). While maintaining the ventilation, the main pulmonary artery and left atrium were cannulated in the opened chest. Using a peristaltic pump, the lungs were perfused with physiologic salt solution with albumin (4 g/100 ml) (Herget and McMurtry 1985) at a constant flow rate $(4 \mathrm{ml} / \mathrm{min} / 100 \mathrm{~g})$. While being ventilated with normoxic $\left(21 \% \mathrm{O}_{2}+5 \% \mathrm{CO}_{2}\right)$ gas mixture, the heart lung block was excised from the body and suspended by the trachea in a heated $\left(38^{\circ} \mathrm{C}\right)$ humid chamber. The outflow cannula from the left atrium was connected into 
the circuit via perfusate reservoir once the outflow was free of blood. Then, the preparation was allowed to stabilize for 30 minutes and the concentration of superoxide and NOx in the perfusate drained from the lungs was measured.

The concentration of NO oxidation products (nitrates and nitrites, NOx), was measured using a chemiluminescence NO analyzer after 30 minutes of perfusion of the isolated lungs in the sample of perfusate from the reservoir. The measured concentration was therefore the result of the accumulation of NOx over 30 minutes. The NOx concentration was recalculated for $1 \mathrm{~g}$ of the lung tissue and expressed in $\mu \mathrm{M} . \mathrm{g}^{-1}$.

The superoxide production was measured using the cytochrome c reduction method (Matsubara and Ziff 1986, Barbacanne et al. 2000). After the stabilisation, the cytochrome c $(25 \mu \mathrm{M})$ and catalase were added into the perfusate (salt solution + albumin) flowing through the isolated lungs. The perfusate sample was collected from the lung outflow and the absorbance was read spectrophotometrically at $550 \mathrm{~nm}$ against distilled water blank. Then the lungs were perfused with salt solution + albumin, cytochrome c, catalase and superoxide dismutase (SOD, $100 \mathrm{U} / \mathrm{ml}$ ). Again, the perfusate sample was collected from the outflow and the absorbance was measured against distilled water blank sample. The reduction of cytochrome $c$ in the presence of SOD was subtracted from the values without SOD. The absorbance differences were converted to equivalent $\mathrm{O}_{2}{ }^{-}$release using the molecular extinction coefficient for cytochrome $\mathrm{c}$ of $21 \mathrm{mM}^{-1} \mathrm{~cm}^{-1}$ (Furchgott and Vanhoutte 1989). The $\mathrm{O}_{2}^{-}$ production was correlated with the lung weight and expressed in $\mu \mathrm{M} . \mathrm{g}^{-1}$.

\section{Hydrogen peroxide detection}

Wistar male rats were divided into 2 groups. The control group $(n=6)$ was kept in room air; the hypoxia group $(n=6)$ was exposed to 4 days of normobaric hypoxia. The animals were then anesthetized (thiopental, $40 \mathrm{mg} / \mathrm{kg}$ intraperitoneally) and the method described by Babbs was used to detect hydrogen peroxide formation in the lung tissue (Babbs 1994). In short, anesthetized rats were intubated and ventilated with room air. The chest was opened, the pulmonary artery was cannulated via the right ventricle and the lungs were perfused with warm saline to remove blood. Then, the ventilation was stopped, the aortic root was ligated and the lungs were perfused with $\mathrm{Fe}^{2+} / \mathrm{DAB}$ buffer saturated with $\mathrm{N}_{2}$ until there was a flow of bubble-free effluent from the trachea.
Consequently, the remaining solution was removed with cold saline and the lungs and heart were perfused with Trump's solution and fixed in $10 \%$ formol. The fixed specimens were dehydrated by a graded series of alcohols, cleared in cedar oil and embedded in paraffin.

Histological slides stained with hematoxylin were scanned using a CCD camera and viewed with an image analyser. 40 fields (objective magnification 20x) were taken from the centre of the left lung (meander). A computer program was used to calculate the circumference of all scanned vessels exclusive of capillaries, their diameter and the length of vessel wall showing $\mathrm{H}_{2} \mathrm{O}_{2}$ formation. The ratio of the length of the vessel wall covered by $\mathrm{H}_{2} \mathrm{O}_{2}$ marker to the circumference of the vessels was then calculated for all vessels.

\section{Statistical analyses}

The results are presented as means \pm S.E.M. They were statistically evaluated by the analysis of variance (ANOVA) and Fisher's PLSD test. The statistical analyses were performed using the statistical software StatView 5.0, SAS Institute Inc (Cary, North Carolina). Differences were considered significant at $\mathrm{p}<0.05$.

\section{Results}

During the hypoxic exposure one experimental animal from the $\mathrm{H} 4$ group died.

In expired air we found higher NO production after 1 and 4 days in hypoxia (Fig. 1). The plasmatic concentration of $\mathrm{NO}$ oxidative products (nitrite $-\mathrm{NO}_{2}{ }^{-}$ and nitrate $-\mathrm{NO}_{3}{ }^{-}$) was significantly increased after 1,4 and 21 days in chronic hypoxia compared to controls (Fig. 2). In the perfusate drained from the isolated ventilated and perfused rat lungs we found the highest NO production after the first day of hypoxic stay, whereas superoxide concentration was at a very low level after the first day and started to increase after 4 days in hypoxia (Fig. 3 and 4).

The plasmatic nitrotyrosine concentration was higher after the first day of hypoxia and rose until the fourth day of hypoxia. We did not find any significant change between day 4 and 21 . In contrast to this, the concentration of LFP in the membranes of erythrocytes was not increased after the first day of hypoxia, than started to rise after 4 days of hypoxia and remained increased until $21^{\text {st }}$ day of hypoxic stay (Table 1). 
Table 1. The plasmatic nitrotyrosine concentration was increased after the first day of hypoxia $(\# p<0.001)$ and continued to increase until the fourth day of hypoxia $(* p<0.05)$. The concentration of LFP in the membranes of erythrocytes started to rise after 4 days of hypoxia and remained significantly increased after 21 days of hypoxic stay $(* p<0.05$, compared to $N$ group).

\begin{tabular}{lcccc}
\hline Measurement & N & H1 & H4 & H21 \\
\hline Nitrotyrosine in plasma $[\mu M]$ & $\mathbf{9 . 0} \pm 0.5$ & $\mathbf{1 1 . 2} \pm 0.7 \#$ & $\mathbf{1 2 . 7} \pm 0.1 *$ & $\mathbf{1 2 . 9} \pm 0.3$ \\
LFP in erythrocytes $\left[r f u . g^{-1}\right.$ prot] & $\mathbf{4 8 . 9} \pm 1.3$ & $\mathbf{5 5 . 3} \pm 2.0$ & $\mathbf{6 3 . 3} \pm 3.0 *$ & $\mathbf{6 8 . 5} \pm 3.3 *$ \\
\hline
\end{tabular}

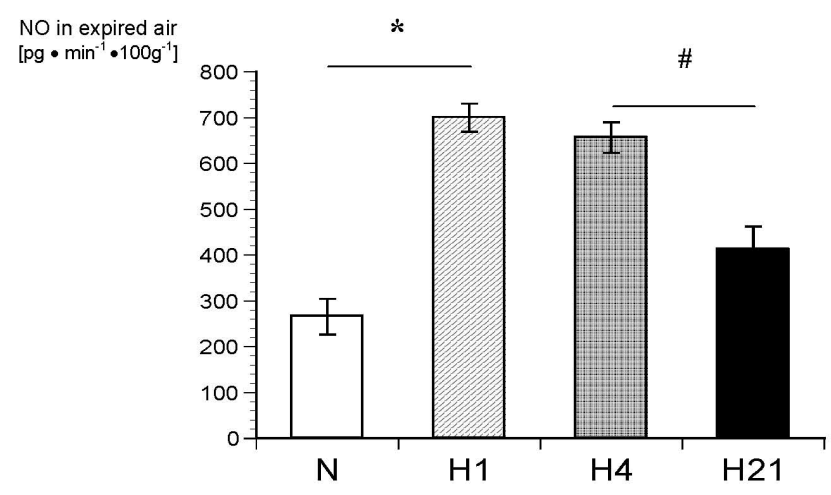

Fig. 1. Production of nitric oxide in the expired air was significantly increased after 1 day in chronic hypoxia and then, after 21 days, decreased $(*, \# p<0.001)$.

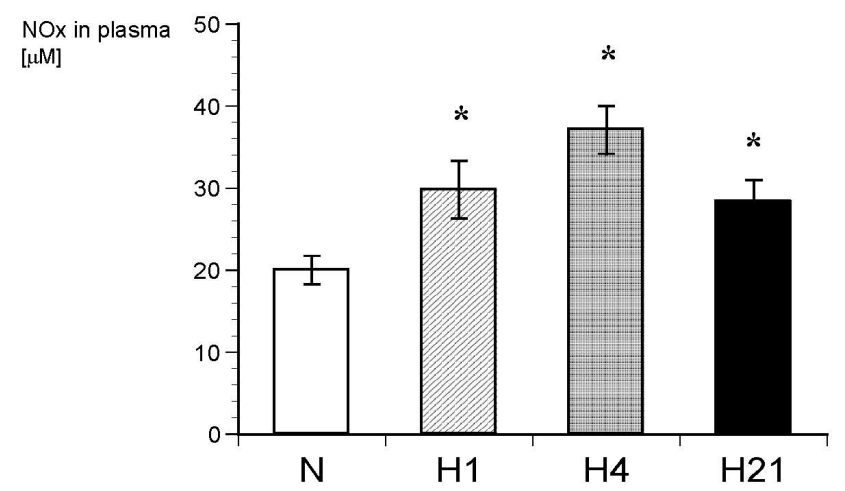

Fig. 2. The plasmatic concentration of $\mathrm{NO}$ oxidative products (nitrite $-\mathrm{NO}_{2}^{-}$and nitrate $-\mathrm{NO}_{3}{ }^{-}$) was significantly increased after 1,4 and 21 days in chronic hypoxia compared to controls $(* \mathrm{p}<0.05)$.

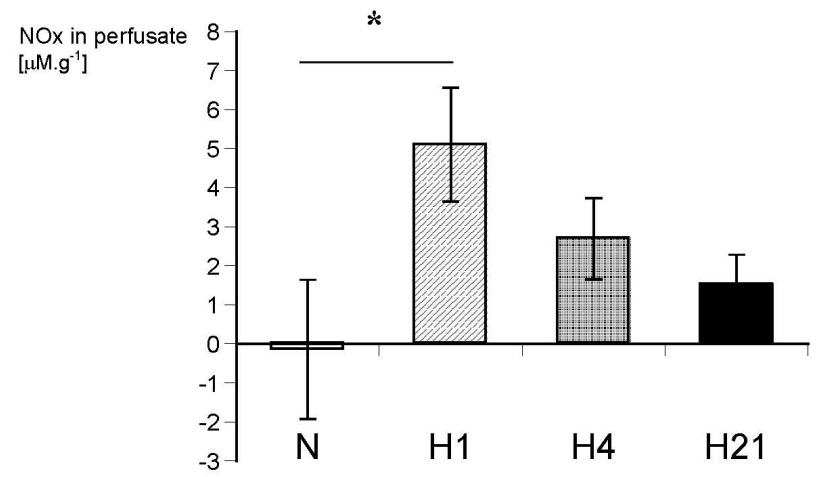

Fig. 3. In the perfusate drained from the isolated ventilated and perfused rat lungs the NOx concentration was significantly increased after the first day of hypoxic sojourn $(* p<0.05)$.

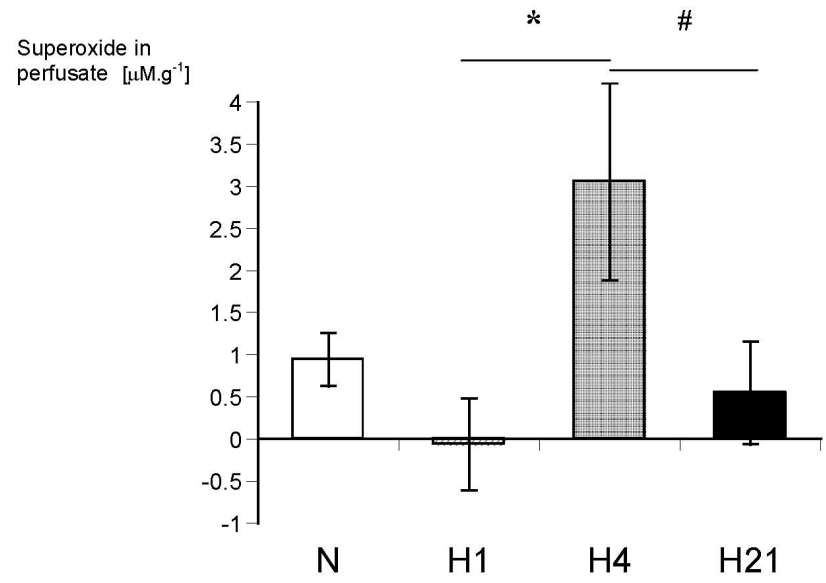

Fig. 4. The concentration of superoxide in the perfusate drained from the isolated lungs was after the first day at a very low level and started to increase after 4 days in hypoxia $(* p<0.01)$; after 21 days in hypoxia it was again significantly decreased (\# $\mathrm{p}<0.05)$.

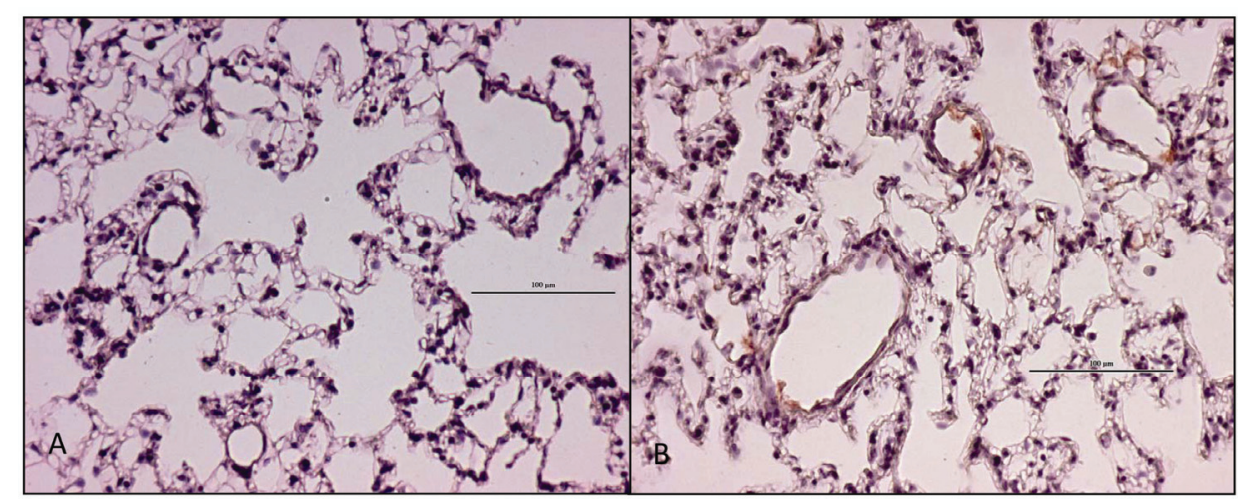

Fig. 5. While there was no hydrogen peroxide in the pulmonary vessels of the control group, we detected $\mathrm{H}_{2} \mathrm{O}_{2}$ formation in $11 \%$ of the vessel walls of the hypoxia-exposed rats $(p<0.01)$. A - Control group: Lungs of control rats with no $\mathrm{H}_{2} \mathrm{O}_{2}$ detection. Objective magnification 20x. B - Hypoxic group: Lungs of rats exposed to 4 day hypoxia. $\mathrm{H}_{2} \mathrm{O}_{2}$ marker shown in vessel lumina. Objective magnification $20 x$. 


\section{Discussion}

The main finding of the presented study is that the production and release of ROS and NO during early phase of chronic hypoxia has specific timing and differs in various compartments. We found that:

1. Production of NO and superoxide rises in the first days of chronic hypoxia; after 3 weeks it either remains in the steady state (plasmatic level of NOx) or decreases (NO in the expired air or NOx produced by isolated lungs).

2. In rats exposed to chronic hypoxia the onset of increased NO production by isolated lungs precedes the increase in superoxide production.

3. Plasmatic level of peroxynitrite (measured as the nitrotyrosine concentration in plasma) rises after the first day of chronic hypoxia; after 4 days in hypoxia it reaches the steady state; in contrast the ROS-induced lipid peroxidation of erythrocytes (measured as the LFP concentration in erythrocyte membranes) starts to increase after 4 days of hypoxia and remains elevated after 3 weeks of chronic ventilatory hypoxia.

This pattern of timing is in agreement with our previous reports, that the pharmacological inhibition of inducible NO synthase (Hampl et al. 2006) and oxidant tissue stress (Lachmanova et al. 2005) in the early phase of exposure to chronic hypoxia, is far more effective than similar treatments applied later in developed HPH. Studies of our group (Wilhelm and Herget 1999b, Herget et al. 2000, Chovanec et al. 2009) and others (Hoshikawa et al. 2001) indicate the oxygen radicals are produced mainly in the onset of exposure to hypoxia and that inhibition of ROS production in early stages of chronic hypoxia prevents the development of HPH (Lachmanova et al. 2005).

The tissue which produces oxygen radicals in chronic hypoxia is not certain. By histochemistry we found hydrogen peroxide mainly in the walls of pulmonary vessels. Earlier we found that hypoxia primes alveolar macrophages to increase the production of hydrogen peroxide (Herget et al. 2000). Hypoxia accelerates the production of ROS, namely superoxide and hydrogen peroxide, in the electron transport chain of mitochondria (Cadenas et al. 1977) or in NADH oxidase (Gupte et al. 2005). Also, smooth muscle cells isolated from pulmonary arteries were shown to produce superoxide under hypoxic conditions. As mentioned in the introduction, studies show that ROS originate mostly from an enzymatic source (Jankov et al. 2008), including xanthine oxidase (Liu et al. 2006) and endothelial nitric oxide synthase (eNOS) converted to a superoxidegenerating enzyme (eNOS uncoupling) (Cai and Harrison 2000, Chalupsky and Cai 2005).

The most probable source of NO release in the early phase of hypoxic exposure is inducible nitric oxide synthase (iNOS) (Hampl et al. 2006). In the current study we have demonstrated that NO production is significantly increased immediately after the first day of hypoxia and the rise in NO production is measurable and significant not only in expired air (NO produced by lungs, airways, nasal and paranasal cavities) and plasma but also in isolated lungs (NO produced only by pulmonary vascular bed and pulmonary cells). On the other hand, in later phases of hypoxia - 4 days and especially after 21 days the change in NO production (compared to normoxic controls) differs between these compartments. In isolated lungs the NO production significantly decreases immediately after 4 days (and is not higher than in normoxic controls), NO production in expired air remains elevated during all 3 weeks of hypoxia, even though after 3 weeks it is significantly reduced (compared to $\mathrm{NO}$ production after 4 days) and in plasma the NO production remains constantly increased for 21 days of hypoxia. This observation is in concordance with the conclusions of our previous study, that in early hypoxia the iNOS is localized mainly in pulmonary vascular media, whereas in more prolonged hypoxic pulmonary hypertension it is also expressed in bronchial epithelia and elsewhere (Hampl et al. 2006).

In rats exposed to chronic hypoxia, the onset of increased NO production by isolated lungs precedes the increase in superoxide production. Two possible explanations are that in the first days the superoxide is either not produced or is rapidly metabolized. Superoxide is rapidly metabolized into another free radical, peroxynitrite, in the presence of nitric oxide and because we have found high levels of NO after one day of hypoxia, we have found the second explanation more plausible. The observed increase in nitrotyrosine plasma concentration indicates the formation of peroxynitrite in the early phase of exposure. The peroxynitrite may be an important factor involved in hypoxia-induced remodelling of prealveolar vessels (Novotna and Herget 2002).

We are aware of the fact that presented conclusions of the experiments are limited by the fact that the measurements of ROS production in different stages of chronic hypoxia were for obvious technical reasons 
done in normoxia. Thus the results might be influenced by the post hypoxic re-oxygenation during the experiment. However, the time from the end of hypoxic exposure to measurements in preparation of isolated perfused lungs was rather short. The NO in expired air was measured immediately (within $30 \mathrm{~s}$ ) after removal from hypoxic chamber. The sampling of perfusate was completed in 20 to $30 \mathrm{~min}$. Moreover, the changes in parameters of oxidant stress due to re-oxygenation of the lung tissue appeared in our studies and studies of other groups usually after longer period with the maximum after 3 days (Ho et al. 1996, Wilhelm and Herget 1999a).

As mentioned previously, it has been demonstrated that nitric oxide, produced in significantly higher amount in the first days of chronic hypoxia, contributes to the development of hypoxic pulmonary hypertension (Hampl et al. 2006). Our explanation, which is in good correlation with the findings presented in this study, is that excessive amount of NO causes higher production of peroxynitrite, leading to the vascular damage and pulmonary hypertension.
The described time pattern of NO and ROS production at the onset of HPH corresponds well with our conception of HPH pathogenesis (Hampl and Herget 2000). HPH is caused by hypoxic injury of prealveolar pulmonary blood vessels due to radical tissue stress. Once HPH develops, it has a non-progressive nature. In rat species in a hypoxic environment, the pulmonary hypertension and right heart hypertrophy develops within the first two weeks of exposure, after which it does not proceed. It then enters the new steady state, with the new level of balance in both tissue oxidant and antioxidant mechanisms. HPH is fully reversible after hypoxia disappears.

\section{Conflict of Interest}

There is no conflict of interest.

\section{Acknowledgements}

The study was supported by the Czech Science Foundation, GACR P303/10/P343, GACR 305/08/0108 and MSMT 1M 0510.

\section{References}

BABBS CF: Histochemical methods for localization of endothelial superoxide and hydrogen peroxide generation in perfused organs. Methods Enzymol 233: 619-630, 1994.

BARBACANNE MA, SOUCHARD JP, DARBLADE B, ILIOU JP, NEPVEU F, PIPY B, BAYARD F, ARNAL JF: Detection of superoxide anion released extracellularly by endothelial cells using cytochrome c reduction, ESR, fluorescence and lucigenin-enhanced chemiluminescence techniques. Free Radic Biol Med 29: 388-396, 2000.

BECKMAN JS: Oxidative damage and tyrosine nitration from peroxynitrite. Chem Res Toxicol 9: 836-844, 1996.

BECKMAN JS, KOPPENOL WH: Nitric oxide, superoxide, and peroxynitrite: the good, the bad, and ugly. Am $J$ Physiol 271: C1424-C1437, 1996.

BELIK J, JANKOV RP, PAN J, TANSWELL AK: Peroxynitrite inhibits relaxation and induces pulmonary artery muscle contraction in the newborn rat. Free Radic Biol Med 37: 1384-1392, 2004.

CADENAS E, BOVERIS A, RAGAN CI, STOPPANI AO: Production of superoxide radicals and hydrogen peroxide by NADH-ubiquinone reductase and ubiquinol-cytochrome c reductase from beef-heart mitochondria. Arch Biochem Biophys 180: 248-257, 1977.

CAI H, HARRISON DG: Endothelial dysfunction in cardiovascular diseases: the role of oxidant stress. Circ Res 87: 840-844, 2000.

CHALUPSKY K, CAI H: Endothelial dihydrofolate reductase: critical for nitric oxide bioavailability and role in angiotensin II uncoupling of endothelial nitric oxide synthase. Proc Natl Acad Sci USA 102: 9056-9061, 2005.

CHOVANEC M, NOVOTNA J, WILHELM J, HAMPL V, VIZEK M, HERGET J: Hypercapnia attenuates hypoxic pulmonary hypertension by inhibiting lung radical injury. Physiol Res 58 (Suppl 2): S79-S85, 2009.

FURCHGOTT RF, VANHOUTTE PM: Endothelium-derived relaxing and contracting factors. FASEB J 3: 2007-2018, 1989.

GOLDSTEIN BD, MCDONAGH EM: Spectrofluorescent detection of in vivo red cell lipid peroxidation in patients treated with diaminodiphenylsulfone. J Clin Invest 57: 1302-1307, 1976.

GUPTE SA, KAMINSKI PM, FLOYD B, AGARWAL R, ALI N, AHMAD M, EDWARDS J, WOLIN MS: Cytosolic NADPH may regulate differences in basal Nox oxidase-derived superoxide generation in bovine coronary and pulmonary arteries. Am J Physiol Heart Circ Physiol 288: H13-H21, 2005. 
HAMPL V, BIBOVA J, BANASOVA A, UHLIK J, MIKOVA D, HNILICKOVA O, LACHMANOVA V, HERGET J: Pulmonary vascular iNOS induction participates in the onset of chronic hypoxic pulmonary hypertension. Am J Physiol Lung Cell Mol Physiol 290: L11-L20, 2006.

HAMPL V, HERGET J: Perinatal hypoxia increases hypoxic pulmonary vasoconstriction in adult rats recovering from chronic exposure to hypoxia. Am Rev Respir Dis 142: 619-624, 1990.

HAMPL V, HERGET J: Role of nitric oxide in the pathogenesis of chronic pulmonary hypertension. Physiol Rev 80: 1337-1372, 2000.

HERGET J, FRYDRYCHOVA M, KAWIKOVA I, MCMURTRY IF: Thyroxine treatment increases the hypoxic pulmonary vasoconstriction in isolated lungs from thyroidectomized rats. Bull Eur Physiopathol Respir 23: 217-221, 1987.

HERGET J, MCMURTRY IF: Effects of ouabain, low $\mathrm{K}^{+}$, and aldosterone on hypoxic pressor reactivity of rat lungs. Am J Physiol 248: H55-H60, 1985.

HERGET J, PALECEK F: Experimental chronic pulmonary hypertension. Int Rev Exp Pathol 18: 347-406, 1978.

HERGET J, WILHELM J, NOVOTNA J, ECKHARDT A, VYTASEK R, MRAZKOVA L, OSTADAL M: A possible role of the oxidant tissue injury in the development of hypoxic pulmonary hypertension. Physiol Res 49: 493$501,2000$.

HO YS, DEY MS, CRAPO JD: Antioxidant enzyme expression in rat lungs during hyperoxia. Am J Physiol 270: L810L818, 1996.

HOSHIKAWA Y, ONO S, SUZUKI S, TANITA T, CHIDA M, SONG C, NODA M, TABATA T, VOELKEL NF, FUJIMURA S: Generation of oxidative stress contributes to the development of pulmonary hypertension induced by hypoxia. J Appl Physiol 90: 1299-1306, 2001.

HOSHIKAWA Y, ONO S, TANITA S, SAKUMA T, NODA M, TABATA T, UEDA S, ASHINO Y, FUJIMURA S: Contribution of oxidative stress to pulmonary hypertension induced by chronic hypoxia. Nihon Kyobu Shikkan Gakkai Zasshi 33: 1169-1173, 1995.

JANKOV RP, KANTORES C, PAN J, BELIK J: Contribution of xanthine oxidase-derived superoxide to chronic hypoxic pulmonary hypertension in neonatal rats. Am J Physiol Lung Cell Mol Physiol 294: L233-L245, 2008.

LACHMANOVA V, HNILICKOVA O, POVYSILOVA V, HAMPL V, HERGET J: N-acetylcysteine inhibits hypoxic pulmonary hypertension most effectively in the initial phase of chronic hypoxia. Life Sci 77: 175-182, 2005.

LIU JQ, ZELKO IN, ERBYNN EM, SHAM JS, FOLZ RJ: Hypoxic pulmonary hypertension: role of superoxide and NADPH oxidase (gp91phox). Am J Physiol Lung Cell Mol Physiol 290: L2-L10, 2006.

MATSUBARA T, ZIFF M: Superoxide anion release by human endothelial cells: synergism between a phorbol ester and a calcium ionophore. J Cell Physiol 127: 207-210, 1986.

NAKANISHI I, TAJIMA F, NAKAMURA A, YAGURA SY, OOKAWARA T, YAMASHITA H, SUZUKI K, TANIGUCHI N, OHNO H: Effects of hypobaric hypoxia on antioxidant enzymes in rats. $J$ Physiol 489: 869$876,1995$.

NOVOTNA J, HERGET J: Possible role of matrix metalloproteinases in reconstruction of peripheral pulmonary arteries induced by hypoxia. Physiol Res 51: 323-334, 2002.

RABINOVITCH M, GAMBLE W, NADAS AS, MIETTINEN OS, REID L: Rat pulmonary circulation after chronic hypoxia: hemodynamic and structural features. Am J Physiol 236: H818-H827, 1979.

REID LM: The pulmonary circulation: remodeling in growth and disease. The 1978 J. Burns Amberson lecture. Am Rev Respir Dis 119: 531-546, 1979.

SUN Y, ZHU Z, LANGNAS AN, GRANT WJ, BOTHA JF, ZHAO Y, SUDAN DL, MERCER DF: Plasma nitrite and nitrate levels as a noninvasive marker of pathology after human small bowel transplantation. Transplantation 89: 307-311, 2010.

WILHELM J, HERGET J: Free radicals in rat lung during and after hypoxia. Physiol Res 48: 53P, 1999a.

WILHELM J, HERGET J: Hypoxia induces free radical damage to rat erythrocytes and spleen: analysis of the fluorescent end-products of lipid peroxidation. Int J Biochem Cell Biol 31: 671-681, 1999b. 